CASE REPORT

\title{
Cushing's syndrome associated with a nested stromal epithelial tumor of the liver: hormonal, immunohistochemical, and molecular studies
}

\author{
Anne Rod ${ }^{1}$, Manuela Voicu ${ }^{2}$, Laurence Chiche ${ }^{3}$, Céline Bazille ${ }^{4}$, Hervé Mittre ${ }^{2,5}$, Estelle Louiset ${ }^{6}$ \\ and Yves Reznik ${ }^{1,5}$ \\ ${ }^{1}$ Unité Fonctionnelle d'Endocrinologie et Maladies Métaboliques, Department of Medicine, CHU Côte de Nacre, 14033 Caen Cedex, France, \\ ${ }^{2}$ Laboratoire de Génétique Moléculaire, CHR Clémenceau, 14033 Caen Cedex, France, ${ }^{3}$ Département de Chirurgie Digestive et Transplantation Hépatique, \\ ${ }^{4}$ Département d'Anatomopathologie, CHU Côte de Nacre, 14033 Caen Cedex, France and ${ }^{5}$ EA 2608-USC INRA, Université de Caen, 14032 Caen Cedex, \\ France and ${ }^{6}$ Laboratoire de Neuroendocrinologie Moléculaire et Cellulaire, INSERM, U-413, Unité affilieé au Centre National de la Recherche Scientifique, \\ Université de Rouen, 76821 Mont St Aignan, France \\ (Correspondence should be addressed to Y Reznik at Unité Fonctionnelle d'Endocrinologie et Maladies Métaboliques, Department of Medicine, \\ CHU Côte de Nacre; Email: reznik-y@chu-caen.fr)
}

(A Rod and M Voicu contributed equally to this work)

\begin{abstract}
Context: Ectopic ACTH syndrome (EAS) is principally associated with aggressive malignant tumors but also with neuroendocrine tumors of good prognosis. Recently, rare nonhepatocytic nested stromal and epithelial tumors (NSET) were characterized by their possible association with Cushing's syndrome of which biochemical and physiopathological features were still incompletely studied.

Objective: To describe the clinical and hormonal characteristics of an EAS originating from a liver NSET and further understand the mechanism of cortisol overproduction.

Design and setting: This is a clinical case report from the Endocrinology Department of Caen University Hospital, France.

Patient and intervention: A 17-year-old female patient was found to have a large liver NSET with mild Cushingoid clinical features and intense biological hypercortisolism but moderate ACTH secretion. Resection of the tumor was curative with a 30-month follow-up.

Results: The epithelial component of the tumor coexpressed ACTH mildly, corticotropin-releasing hormone (CRH) strongly, and 11 $\beta$-hydroxysteroid dehydrogenase at a level comparable with normal human hepatocytes.

Conclusions: Liver NSET is a new cause of EAS, which may evoke hypercortisolism by multiple biochemical pathways.
\end{abstract}

European Journal of Endocrinology 161 805-810

\section{Introduction}

Ectopic ACTH syndrome (EAS) represents $9-18 \%$ of all causes of Cushing's syndrome (1-3). EAS is mainly associated with either highly malignant tumors such as small cell lung carcinoma or less aggressive tumors such as pulmonary or mediastinal carcinoids, but also pancreatic and thymic carcinoids, gastrinoma, pheochromocytoma, and medullary thyroid cancer. Recently, rare cases of nonhepatocytic mixed nested stromal and epithelial tumors (NSET) of the liver were reported by two different groups, and their histopathologic and immunohistochemical features were extensively described $(4,5)$. Of 22 cases reported in the literature, few were associated with Cushing's syndrome which clinical and biochemical characteristics were partially described $(4,6)$. In the present report, we describe the occurrence of a NSET of the liver in a teenage girl who developed EAS originating from combined production of ACTH and corticotropinreleasing hormone (CRH) by the tumor. The histopathological and immunological characteristics of the tumor are described, and the mechanism of cortisol overproduction is under investigation.

\section{Patient and methods}

\section{Patient}

A 17-year-old girl with no past medical history was referred for persistent asthenia in December 2005. She complained about the rapid occurrence of facial edema and mild acne. Physical examination revealed a palpable right upper abdominal mass. Ultrasound and computed tomography (CT) scan confirmed 


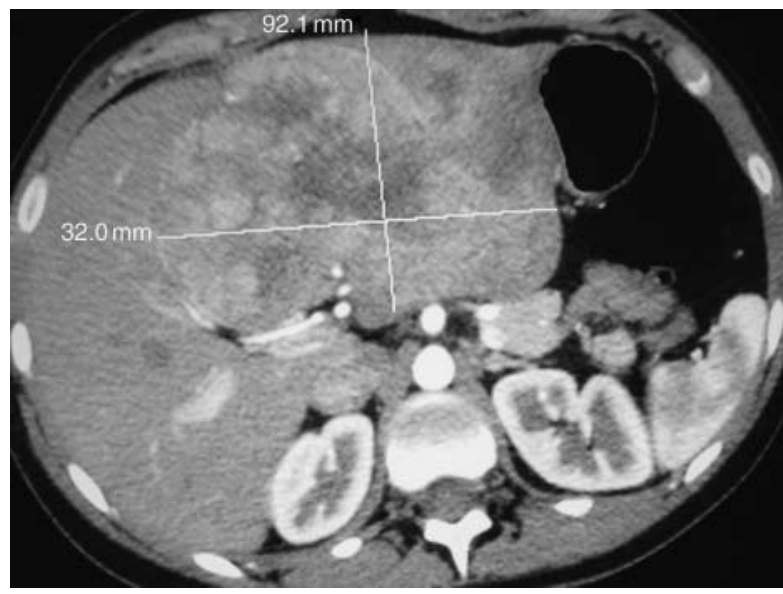

Figure 1 CT scan shows a $132 \times 92 \mathrm{~mm}$ diameter heterogeneous and partially calcified mass of the left liver.

a $132 \times 92 \mathrm{~mm}$ diameter well circumscribed but heterogeneous and partially calcified mass of the left liver with foci of necrosis (Fig. 1). Laboratory findings included $\gamma$-glutamyl transferase up to sixfold above the normal range, 24-h urinary free cortisol at $3490 \mathrm{nmol}$ (normal range 55-275), plasma cortisol and plasma ACTH respectively at $660 \mathrm{nmol} / \mathrm{l}$ and $25 \mathrm{pmol} / \mathrm{l}$ at $0800 \mathrm{~h}$ (normal range $276-690 \mathrm{nmol} / \mathrm{l}$ and 4-21 pmol/l respectively) and at $798 \mathrm{nmol} / \mathrm{l}$ and $27 \mathrm{pmol} / \mathrm{l}$ at $0000 \mathrm{~h}$ (normal range $<207 \mathrm{nmol} / \mathrm{l}$ and $<2.2 \mathrm{pmol} / \mathrm{l}$ respectively). The standard high dose dexamethasone suppression test resulted in partial decrease in 24-h urinary free cortisol $(1650 \mathrm{nmol})$. Magnetic resonance imaging of the skull showed a normal pituitary gland, and CT scan of the thorax was normal. Thyroid function testing, prolactin, and gonadotropin levels were in the normal range. Tumor markers ACE, CA 15-3, CA 19-9, NSE and $\alpha$-fetoprotein were all in the normal range except $\beta$-LPH at $366 \mathrm{pg} / \mathrm{ml}$ (normal range $85 \pm 39$ ). Tomography emission positron imaging showed increased uptake of ${ }^{18}$ F-fluoride in the liver, while no uptake of 111In-pentetreotide was observed on liver scintigraphy. The patient rapidly underwent left hepatectomy with apparent complete removal of the tumor. Two months after surgery, facial edema and acne had resolved. Cortisol/ACTH circadian rhythm was restored, and 24-h urinary free cortisol and plasma $\beta$-LPH were in the normal range $(55 \mathrm{nmol} /$ day and $61 \mathrm{pg} / \mathrm{ml}$ respectively), without hypoadrenalism as stated by the cortisol response to the $250 \mu \mathrm{g}$ standard ACTH test $(567 \mathrm{nmol} / \mathrm{l})$. However, $0800 \mathrm{~h}$ plasma ACTH was low $(2.6 \mathrm{pmol} / \mathrm{l})$ and $0800 \mathrm{~h}$ plasma cortisol in the low normal range $(276 \mathrm{nmol} / \mathrm{l})$, suggesting a mild pituitary ACTH suppression consecutive to previous hypercortisolism. Histological examination of the tumor showed a typical nested spindled and epithelioid cell tumor with stromal proliferation, calcifications, and neuroendocrine differentiation (Fig. 2). Because distant metastatic disease or death due to this category of tumor was never reported at the time of surgery and resection was complete, no
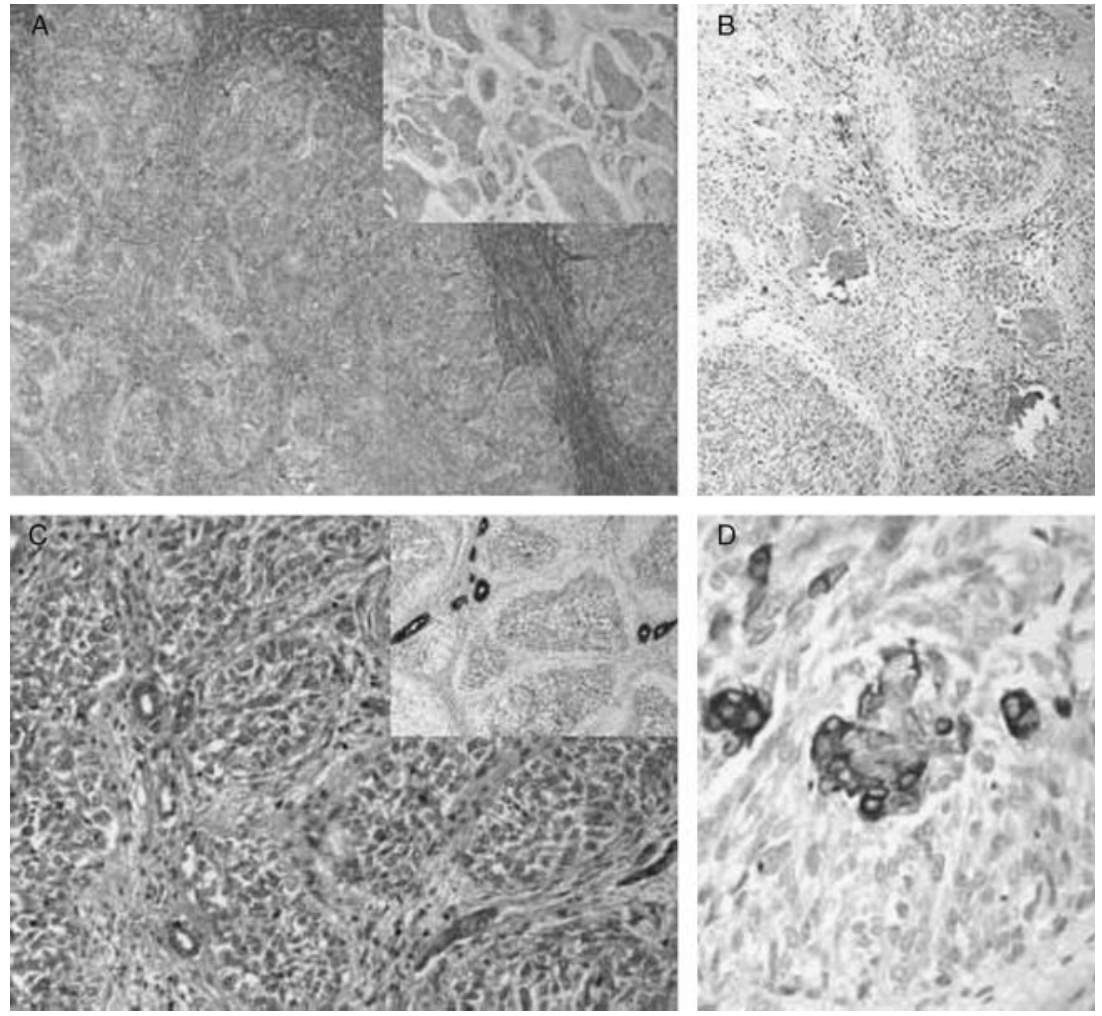

Figure 2 Pathological features: biphasic architecture with cellular nests in a desmoplastic stroma. Notice the entrapped hepatocyte bundle on the left (A). CD56 immunohistochemical stain in nest cells (A, inset). Focal osteoid formation in nest cells (B). Hematoxylin, eosin, and saffron (HES), original magnification $\times 100(A)$, $\times 200$ (B). Higher magnification showing epithelioid nest cells with well-defined cell borders and regular nuclei $(C, \mathrm{HES}, \times 400)$ . Pancytokeratin immunostaining showed slight cytoplasmic positivity of nests and highlighted entrapped bile ducts (C, inset). ACTH immunohistochemical stain demonstrating focal cytoplasmic accumulation in epithelioid cells (D). 
complementary chemotherapy was administered. At this time, the patient remains free of apparent residual disease after a 30-month follow-up.

\section{Microscopic and immunohistochemical analysis}

All immunochemical stains were performed on sections of $10 \%$ formaldehyde-fixed, paraffin-embedded tissue. The tumor cells were characterized immunohistochemically with an antibody cocktail to pancytokeratin (1:200, DakoCytomation, Carpinteria, CA, USA), vimentin (1:200, Dako), epithelial membrane antigen (1:50, Dako), and the neuroendocrine marker CD56 (1:50, Novocastra, Norwell, MA, USA). The desmoplastic stromal cells were characterized with an antibody to smooth muscle actin (1:50, Biogenex, San Remon, CA, USA). Bile ductular cells were characterized with an antibody to cytokeratin 7 (1:200, Dako). ACTH immunoreactivity was characterized with a polyclonal antibody (1:10, Dako). Antibodies to hepatocyte (hepatocyte antigen) and to neuroendocrine markers (chromogranin and synaptophysin, CD99, $\alpha$-inhibin and estrogen, and progesterone receptors) were also used to characterize hepatocyte cells and neuroendocrine cells respectively.

\section{Quantitative PCR for POMC, 11 $\beta$-HSD1, and CRH mRNA}

Total RNA were isolated from tumor and normal tissue as described by Chomczynski (7). RT was performed at $37^{\circ} \mathrm{C}$ for $60 \mathrm{~min}$ in presence of $1 \mu \mathrm{g}$ of total RNA, using 50 pmol oligodT $\mathrm{T}_{12-18}, 0.2 \mathrm{mM}$ of each deoxynucleotide triphosphate, $10 \mathrm{mM}$ dithiothreitol, $5 \mathrm{U}$ of RNasin and 200 U Moloney murine leukemia virus-RT (Invitrogen) in a final volume of $40 \mu \mathrm{l}$. The reaction was terminated by the inactivating enzyme at $95{ }^{\circ} \mathrm{C}$ for $5 \mathrm{~min}$. The cDNA obtained was measured by quantitative RT-PCR using Power SYBGreen kit (Applied Biosystems). Realtime PCR was performed in $30 \mu \mathrm{l}$ reactions and carried out in ABIPRISM7000 system (Applied Biosystems). The thermal cycling conditions included an initial activation step at $95{ }^{\circ} \mathrm{C}$ for $10 \mathrm{~min}$, followed by 40 cycles of denaturation, annealing, and amplification $\left(94{ }^{\circ} \mathrm{C}\right.$ for $15 \mathrm{~s}, 60^{\circ} \mathrm{C}$ for $\left.1 \mathrm{~min}\right)$. The forward primer sequence for POMC was $5^{\prime}$-CAGCCAGTGTCAGGACCTC- $3^{\prime}$ and the reverse primer sequence was 5'-GGTCAGAGGCTGCTCGTC-3' (gene accession number NM_000939, primer position 306-426). The forward primer sequence for $11 \beta$-hydroxysteroid dehydrogenase enzyme type 1 (11 $\beta$-HSD1) was $5^{\prime}$-TCTCTGTGTTCTTGGCCTCA- $3^{\prime}$ and the reverse primer sequence was 5'-ATGATCTCCAGGGCACATTC-3' (gene accession number NM_005525, primer position 730-834). The forward primer sequence for CRH was 5'-AGAGAAAGCCCCCGGAGA- $3^{\prime}$ and the reverse primer sequence was 5'-GAGAGCCACCAGCAGGACTC-3' (gene accession number NM_000756, primer position 99-233). The cDNA of the housekeeping gene $\beta$-glucuronidase (GUS) was used as a normalizer with the forward primer sequence $5^{\prime}$-CTCATTTGGAATTTTGCCCATT- ${ }^{\prime}$ and with the reverse primer sequence 5'-CCGAGTGAAGATCCCCTTTTTA-3' (gene accession number NM_000181, primer position 1829-1909). All mRNA quantifications were expressed as a ratio to GUS mRNA, since GUS is a housekeeping gene encoding for a liver lysosomal GUS, which is present at stable expression levels in tumor and normal human liver.

\section{Results}

\section{Histological examination}

The left hepatectomy specimen weighed $1650 \mathrm{~g}$ and contained a $150 \times 90 \mathrm{~mm}$ tumor. Grossly, the tumor appeared well circumscribed, not encapsulated, with a multilobulated tan-white cut surface. Margins were in uninvolved liver. Histological features were consistent with NSET: the tumor displayed an arrangement of cellular nests comprising spindled and/or epithelioid cells in a prominent desmoplastic stroma (Fig. 2A). Nuclear membranes were well defined, chromatin was fine, and only scattered mitotic figures were identified without atypical mitosis (Fig. 2C). Psammomatous calcifications and focal osteoid formation were present (Fig. 2B). Bile ducts and cords of hepatocytes were entrapped between the tumor cell nests (Fig. 2A). No component of the tumor exhibited the characteristics of steroidogenic cells.

\section{Immunohistochemical analysis}

Immunostaining revealed that the tumor cells co-expressed vimentin, the neuroendocrine marker CD56 (Fig. 2A, inset), and the pancytokeratin cocktail (Fig. 2C, inset) in nest cells and bile ducts inside the tumor. The keratin 7 highlighted the entrapped bile ducts within the tumor. Foci of epithelial membrane antigen staining were observed in the tumor (data not shown). Foci of ACTH staining were present in epithelioid cells (Fig. 2D). Smooth muscle actin was prominently displayed in the desmoplastic stroma (data not shown). The hepatocyte antigen, the neuroendocrine markers chromogranin and synaptophysin, CD99, $\alpha$-inhibin, and steroid hormone receptors were negative. The diagnosis of Ewing sarcoma or synovial sarcoma was excluded by molecular studies of SYT SSX and EWS WT1.

\section{RT-PCR for POMC, $11 \beta$-HSD1, and CRH MRNA}

POMC mRNA quantification showed an intense expression in NSET liver cells, as compared with normal hepatocyte cells, placental, and adrenocortical control 



nested stromal and epithelial tumors, normal human hepatocytes, fetal placenta, and adrenal cortex. All data are expressed as a ratio to $\beta$-glucuronidase (GUS) mRNA.

\begin{tabular}{llll}
\hline & POMC/GUS mRNA & 11ß-HSD1/GUS mRNA & CRH/GUS mRNA \\
\hline Liver NSET & $4.6 \pm 0.19(n=4)^{\mathrm{a}}$ & $0.022 \pm 0.003(n=4)^{\mathrm{a}}$ & $135 \pm 10(n=4)^{\mathrm{a}}$ \\
Human hepatocytes & $<10^{-4}(n=8)^{\mathrm{b}}$ & $0.194 \pm 0.152(n=7)^{\mathrm{b}}$ & $<10^{-4}(n=4)^{\mathrm{c}}$ \\
Human fetal placenta & $0.075 \pm 0.041(n=4)^{\mathrm{d}}$ & $0.015 \pm 0.009(n=4)^{\mathrm{d}}$ & $1.67 \pm 0.99(n=4)^{\mathrm{d}}$ \\
Human adrenal cortex & $0.56 \pm 0.13(n=8)^{\mathrm{e}}$ & $0.004 \pm 0.001(n=8)^{\mathrm{e}}$ & $0.0024 \pm 0.0003(n=8)^{\mathrm{e}}$ \\
\hline
\end{tabular}

${ }^{\text {a }}$ Four independent measures from one tumor sample.

${ }^{b}$ Eight independent measures from two normal liver tissue samples.

${ }^{c}$ Four independent measures from one normal liver tissue sample.

${ }^{\mathrm{d}}$ Four independent measures from one normal fetal placenta tissue sample.

eEight independent measures from two normal adult adrenal tissue samples.

cells, which expressed low if any POMC mRNA level (Table 1). The possibility that active cortisol (F) should be generated from the inactive circulating cortisone (E) by overexpression of the $11 \beta$-HSD1 in the tumor tissue was investigated by measuring $11 \beta$-HSD1 mRNA in NSET liver cells. 11 $\beta$-HSD1 mRNA was detected at low level in NSET liver cells, normal hepatocyte cells, and in human fetal placental cells, and in minute amounts if any in adrenal control tissues (Table 1). An ectopic expression of $\mathrm{CRH}$ was investigated by the measurement of CRH mRNA in NSET liver cells. CRH mRNA quantification showed an 80-fold overexpression in NSET liver cells in comparison with normal human fetal placenta, while CRH mRNA was detected at low level if any in normal hepatocytes and in adrenal control tissues (Table 1).

\section{Discussion}

Mixed neoplasms of the liver were scarcely described, and very few tumors encompassing stromal, epithelial, and osteoid lineages have been reported previously $(4,5,8)$. These NSET characteristically display an arrangement of cellular nests composed of spindled or epithelioid cells surrounded by a desmoplastic stroma $(4,5)$. Twenty-two cases were reported in the literature, eleven occurring during infancy $(4,5,9,10)$, seven in teenagers $(4-6,10)$, and only four cases in the adult $(10,11)$. Four cases of liver NSET associated with Cushing's syndrome were reported in two children with ACTH-dependent hypercortisolism (4) and in two teenagers $(6,10)$, but these cases were partially described. The prognosis of NSET remains unpredictable due to its scarcity. Nevertheless, among the 22 cases reported in the literature, three have had local hepatic recurrence of the disease, one with lymph node metastasis, but none with disant metastasis $(4,6,10)$.

This report is the first to analyze the biochemical and molecular characteristics of this EAS-associated NSET in order to explain the Cushing phenotype. Our observation displays several comments concerning the clinical and biochemical features of this unusual EAS: first, the clinical expression of Cushing's syndrome in this patient was limited to rounded face and mild acne and contrasted with gross cortisol overproduction, as evidenced by the sixfold increase above the normal range of 24-h urinary free cortisol. These features may be explained by the rapid proliferation of this neoplasm and therefore a presumably short time course of the disease. Second, this case enters the definition of EAS since i) it displays the clinical and biochemical characteristics of tumor-associated abnormal endocrine function, ii) complete removal of the tumor was rapidly followed by the disappearance of the endocrine disturbances, and iii) the presence of ACTH immunostaining and POMC mRNA was demonstrated in the epithelioid component of the tumor as in the placental control tissues (12). The plasma ACTH levels measured before surgery remained in the range usually found in Cushing's disease, a finding frequently reported in ectopic ACTH-producing tumors $(1,13)$. However, such moderate elevation of plasma ACTH levels contrasted with the frank hypercortisolism demonstrated by very high free urinary cortisol level. This discordance together with mild ACTH overexpression suggested by the scarce ACTH-immunostaining signal in the tumor cells prompted us to explore alternative mechanism(s) for explaining cortisol overproduction. The 11ß-HSD1 is expressed in glucocorticoid target tissues including the liver where it carries the $11 \beta$ oxoreductase and $11 \beta$-dehydrogenase activities, which enables the conversion of cortisone into the active glucocorticoid compound cortisol $(14,15)$. We therefore investigated the possibility that such liver NSET may overexpress the $11 \beta$-HSD1 enzyme and may generate huge amounts of cortisol from its circulating substrate cortisone, thus explaining the massive cortisol overproduction. The finding of $11 \beta-H S D 1$ mRNA expression in the liver NSET at similar level than normal human liver and placental control tissues makes such hypothesis unlikely $(14,16)$. Nevertheless, we cannot exclude that liver NSET 11 $\beta$-HSD1 may participate in extra-adrenal cortisol overproduction despite the weak expression of the enzyme, due to the huge tumor mass. In the same way, the hypothesis that the liver NSET should exhibit steroidogenic properties for producing cortisol is not supported by the 
histological aspect of the different cell components of the tumor.

In order to explain the discordance between the high level of hypercortisolism and the mild degree of ACTH overexpression in the tumor cells, we raised the possibility that this NSET may express another hormone triggering the pituitary-adrenal axis. We therefore measured the expression of $\mathrm{CRH}$ mRNA in tumor extracts and found high levels in the liver NSET compared with fetal placental control tissue (17), while normal human liver did not express $\mathrm{CRH}$. This finding suggested that ectopic $\mathrm{CRH}$ originating from the NSET may have triggered the pituitary production of ACTH, thus stimulating adrenal cortisol overproduction. The characteristic features of ectopic $\mathrm{CRH}$ syndrome associate pituitary hyperplasia of the corticotropes and high CRH circulating levels. We were not able to measure the peripheral $\mathrm{CRH}$ concentrations and the ACTH petrosal sinus to peripheral ratio before surgery, in order to reinforce this hypothesis. Alternatively $\mathrm{CRH}$ produced by the tumor may have triggered the local production of ACTH in a paracrine or autocrine fashion. This hypothesis of the tumoral source of circulating plasma ACTH is reinforced by the finding that 2 months after tumor resection, the pituitary ACTH secretion was low, suggesting the suppression of pituitary ACTH secretion during the active phase of the disease rather than its stimulation by circulating CRH. The low level of ACTH immunoreactivity in the tumor tissue may thus be explained by reduced ACTH storage (18).

ACTH/CRH coexpression in EAS was first described by Upton and Amatruda in 1971 (19) and is of rare occurrence since Wajchenberg et al. recorded only 13 similar cases in a 23-year period (1). Most cases were carcinoid tumors and metastatic lung oat cell carcinomas. The occurrence of EAS in a liver tumor is extremely rare, as shown by two recent series of EAS reporting 40 and 90 cases respectively but none including a liver tumor $(13,20)$.

In conclusion, liver NSET represents a new cause of EAS associated with Cushing's syndrome, which in the present case probably was the consequence of ACTH and $\mathrm{CRH}$ cosecretion by the tumor, which stimulated cortisol overproduction by the host adrenal glands.

\section{Declaration of interest}

We declare that there is no conflict of interest that could be perceived as prejudicing the impartiality of the research reported.

\section{Funding}

This research did not receive any specific grant from any funding agency in the public, commercial, or not-for-profit sector.

\section{Author contribution statement}

Anne Rod and Manuela Voicu contributed equally to this work.

\section{Acknowledgements}

We thank Vincent Roulleau for his participation in the immunohistochemical experiments and Hervé Lefebvre for fruitful discussions.

\section{References}

1 Wajchenberg BL, Mendonca BB, Liberman B, Albergaria Pereira MA, Campos Carneiro P, Wakamatsu A \& Kirschner MA. Ectopic adrenocorticotropic hormone syndrome. Endocrine Reviews $199415752-787$.

2 Aniszewski JP, Young WF, Thompson GB, Grant CS \& van Heerden JA. Cushing's syndrome due to ectopic adrenocorticotropic hormone secretion. World Journal of Surgery 2001225 934-940.

3 Invitti C, Giraldi FP, De Martin M \& Cavagnini F. Diagnosis and management of Cushing's syndrome: results of an Italian multicentre study. Journal of Clinical Endocrinology and Metabolism $199984440-448$.

4 Heerema-McKenney A, Leuschner I, Smith N, Sennesh J \& Finegold MJ. Nested stromal epithelial tumor of the liver. Six cases of a distinctive pediatric neoplasm with frequent calcifications and association with Cushing's syndrome. American Journal of Surgical Pathology 200529 10-20.

5 Hill DA, Swanson PE, Anderson K, Covinsky MH, Finn LS, Ruchelli ED, Nascimento AG, Langer JC, Minkes RK, McAlister W \& Dehner LP. Desmoplastic nested spindle cell tumor of liver: report of four cases of a proposed new entity. American Journal of Surgical Pathology 200529 1-9.

6 Brodsky S, Sandoval C, Sharma N, Yusuf Y, Facciuto M, Humphrey M, Yeh Y, Braun A, Melamed M \& Finegold M. Recurrent nested stromal epithelial tumor of the liver with extrahepatic metastasis: case report and review of literature. Pediatric and Developmental Pathology 2008 11 469-473.

7 Chomczynski P \& Sacchi N. Single-step method of RNA isolation by acid guanidinium thiocyanate-phenol-chloroform extraction. Analytical Biochemistry $1987 \mathbf{1 6 2} 156-159$.

8 Heywood G, Burgart LJ \& Nagorney DM. Ossifying malignant mixed epithelial and stromal tumor of the liver. A case report of a previously undescribed tumor. Cancer 200294 1018-1022.

9 Meir K, Maly A, Doviner V, Gross E, Weintraub M, Rabin L \& Pappo O. Nested (ossifying) stromal epithelial tumor of liver: case report. Pediatric and Developmental Pathology 200912 233-236.

10 Makhlouf HR, Abdul-Al HM, Wang G \& Goodman ZD. Calcifying nested stromal-epithelial tumors of the liver: a clinicopathologic, immunohistochemical and molecular genetic study of 9 cases with a long-term follow-up. American Journal of Surgical Pathology 2009 33 976-983.

11 Grazi GL, Vetrone G, d'Errico A, Caprara G, Ercolani G, Cescon M, Ravaioli M, Del Gaudio M, Vivarelli M, Zanello M \& Pinna AD. Nested stromal-epithelial tumor (NSET) of the liver: a case report of an extremely rare tumor. Pathology, Research and Practice, 2009. In Press DOI: 10.1016/j.prp.2009.04.012.

12 Cooper ES, Greer IA \& Brooks AN. Placental proopiomelanocortin gene expression, adrenocorticotropin tissue concentrations, and immunostaining increase throughout gestation and are unaffected by prostaglandins, antiprogestins, or labor. Journal of Clinical Endocrinology and Metabolism $1996814462-$ 4469.

13 Isidori AM, Kaltsas GA, Pozza C, Frajese V, Newell-Price J, Reznek RH, Jenkins PJ, Monson JP, Grossman AB \& Besser GM. The ectopic adrenocorticotropin syndrome: clinical features, diagnosis, management, and long-term follow-up. Journal of Clinical Endocrinology and Metabolism 200691 371-377. 
14 Stewart PM. Tissue-specific Cushing's syndrome, $11 \beta$-hydroxysteroid dehydrogenases and the redefinition of corticosteroid hormone action. European Journal of Endocrinology 2003149 163-168.

15 Maser E, Völker B \& Friebertshäuser J. 11Beta-hydroxysteroid dehydrogenase type 1 from human liver: dimerization and enzyme cooperativity support its postulated role as glucocorticoid reductase. Biochemistry 200241 2459-2465.

16 Sun K, Yang K \& Challis JRG. Differential expression of $11 \beta$ hydroxysteroid dehydrogenase types 1 and 2 in human placenta and fetal membranes. Journal of Clinical Endocrinology and Metabolism 199782 300-305.

17 Frim D, Emanuel R, Robinson B, Smas C, Addler G \& Majzoup J. Characterisation and gestational regulation of $\mathrm{CRH}$ in human placenta. Biochemical and Biophysical Research Communications 198882 287-292.

18 Carey RM, Varma SK, Drake CR Jr, Thorner MO, Kovacs K, Rivier J \& Vale W. Ectopic secretion of corticotropin-releasing factor as a cause of Cushing's syndrome. A clinical, morphologic, and biochemical study. New England Journal of Medicine 1984 311 13-20.

19 Upton GV \& Amatruda TT Jr. Evidence for the presence of tumor peptides with corticotropin-releasing-factor-like activity in the ectopic ACTH syndrome. New England Journal of Medicine 1971 285 419-424.

20 Ilias I, Torpy DJ, Pacak K, Mullen N, Wesley RA \& Nieman LK. Cushing's syndrome due to ectopic corticotropin secretion: twenty year's experience at the National Institutes of Health. Journal of Clinical Endocrinology and Metabolism 200590 4955-4962.

Received 31 July 2009

Accepted 4 August 2009 